\title{
Research on On-line Monitoring Technology of Secondary Equipment in Smart Substation
}

\author{
Hongming Shen ${ }^{1 *}$, Peili Yan ${ }^{1}$, Teng Feng ${ }^{1}$, Ziqi Wang ${ }^{1}$, WenXuan Liu ${ }^{1}$, Jing Jiang ${ }^{1}$, Min Liu ${ }^{1}$, Na Du ${ }^{1}$ \\ ${ }^{1}$ State Grid Economic and Technological Research Institute Co., Ltd, Beijing, 102209, China
}

\begin{abstract}
First, the overall design principles of the online monitoring of secondary equipment in smart substations are studied. Then, the overall architecture of online monitoring of secondary equipment is proposed. Finally, the advanced application of the online monitoring system of secondary equipment is analyzed. The method proposed in this paper improves the online monitoring and management level of secondary equipment, and provides technical support for the regulation and condition maintenance of secondary equipment.
\end{abstract}

\section{Introduction}

The substation is an important node for the collection and conversion of electric energy in the power system. Secondary devices, such as protection, measurement and control are all important equipment to ensure the stable operation of the substation. Therefore, the reliable operation of the secondary equipment is the basis for the power system stability. The intelligent substation has added process-level equipment such as merging units and intelligent terminals, which highlights the characteristics of digitization, networking, and intelligence, which provides the possibility for online monitoring of secondary equipment.

Ref. [1] analyzes the complex information flow modeling method of smart substations, and provides a theoretical basis for using the rich information flow information of smart substations to realize online monitoring of primary and secondary equipment. At present, the online monitoring technology of primary equipment is relatively mature [2-5], especially oil chromatography online monitoring [6], arrester leakage current monitoring [7] and other technologies have been applied in actual projects, but for secondary equipment online monitoring Less technical research. Ref. [8] realizes online monitoring and status maintenance of secondary equipment by real-time monitoring of SV/GOOSE information of smart substations, focusing on the monitoring of the status of information flow of smart substations, and the fault division of secondary equipment is not fine enough; Ref. [9-10]Using the characteristics of digitalization and networking of smart substations, the status monitoring of relay protection equipment is realized; Ref. [11] proposes the aging prevention and monitoring technology of secondary equipment DC power plug-in; Ref. [12] proposes secondary equipment of smart substation condition monitoring technology, but does not systematically give the overall architecture and implementation route.

\section{Overall architecture research}

\subsection{Overall vision}

The secondary equipment online monitoring and analysis technology realizes rapid analysis of grid faults, equipment status diagnosis, power grid and equipment by collecting, processing, and uploading the information of secondary equipment such as relay protection, self-installation devices, and fault recorders at the plant and station. The risk analysis and other functions of the company provide support for operations such as dispatch operation, operation, maintenance, and repair.

\subsection{Design Principles}

(1) Standardized and rational use of security zones.

(2) Advanced applications are restructured based on the control cloud construction to support the development of various businesses in the protection profession.

(3) Utilize and support the construction and development of big data in the control center.

(4) Make full use of technologies such as mobile terminals and artificial intelligence to improve user experience and work safety.

\subsection{Overall structure}

The overall system architecture designed according to the above principles is shown in Fig. 1. 


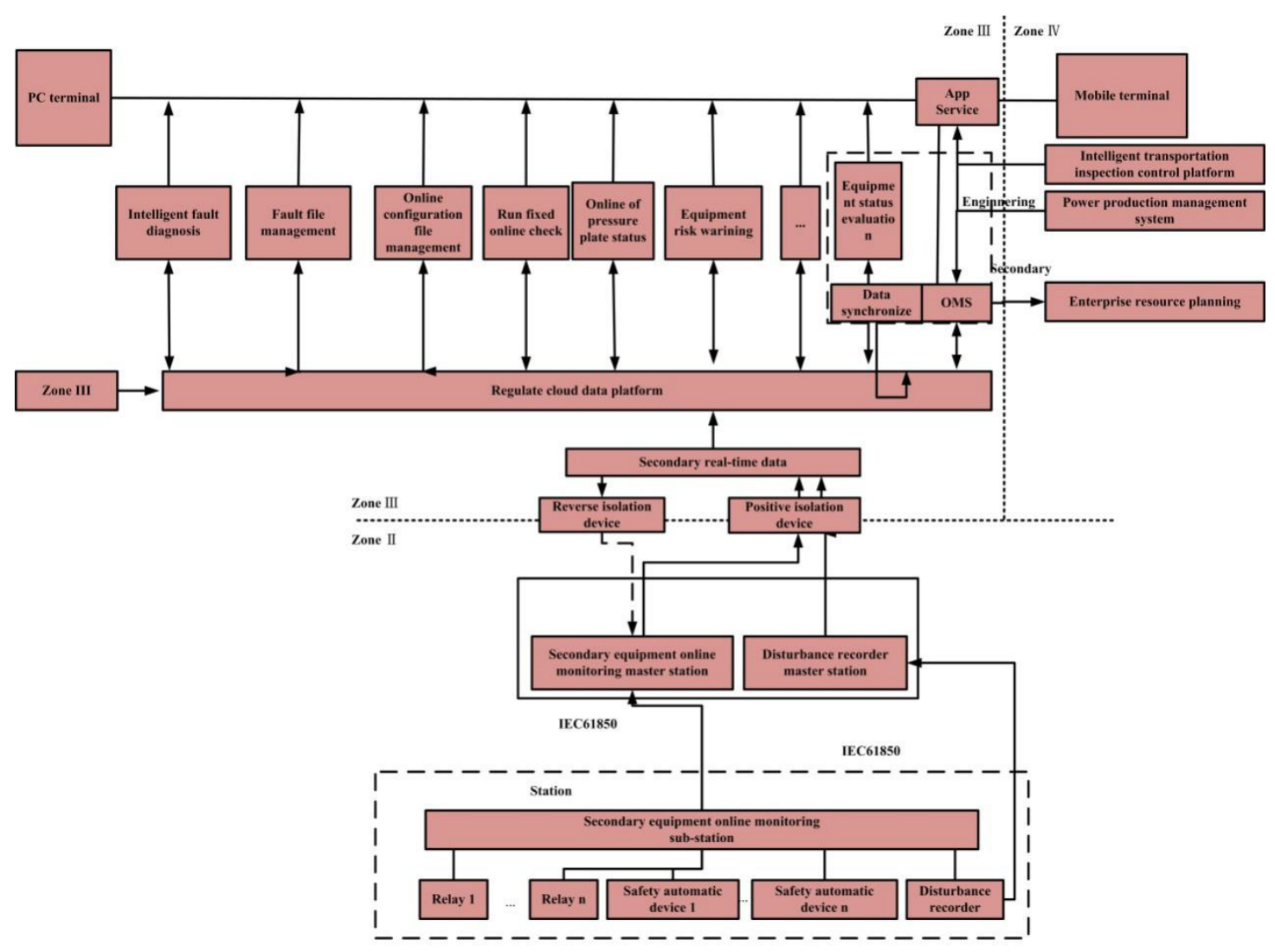

Fig.1 Overall architecture diagram of online monitoring of secondary equipment

In Fig. 1, the security zone II is mainly used to collect protect information; the security zone III deploys protection application functions to provide access services to computer terminals and mobile terminal users in Zone III/IV. Information collection in Zone II takes into account the technical status and capabilities of the new and old substations. The protection information substations of the already operating substations can continue to be used. The new substations deploy secondary equipment online monitoring and analysis substations, without the need to deploy protection information substations; protect real-time data It is output to Zone III through the isolation device and stored in the control cloud data platform.

All relay protection applications in Zone III are reconstructed based on the control cloud to support the main application functions of the protection profession (the application part in Figure 1 only lists the main application functions). Application interaction has changed from data interface between systems to use of cloud platform for data sharing. Based on the cloud platform, applications are integrated and connected to support the construction and development of central-level big data. The OMS system transplanted to the control cloud will serve as a unified external window to realize interaction with external systems such as PMS,
ERP, ECP, and intelligent transportation inspection management and control platform. The identification mechanism will gradually transition from system-based identification to physical ID identification. The mobile terminal and the PC terminal are treated the same, with complementary functions and advantages. The functions are developed simultaneously. The interface and operation are based on a unified role and authority configuration.

\section{Main advanced applications}

\subsection{Intelligent fault diagnosis}

After each power grid failure, the power grid fault diagnosis report is automatically generated and the diagnosis report can be archived and managed. The diagnosis report includes information such as the nature of the fault, the fault location result, the trip phase, the setting value of the protection device, and the judgment of whether the reclosing is successful. Conclusion, and push it to authorized computer terminal and mobile terminal users. The schematic diagram is shown in Fig.2. 


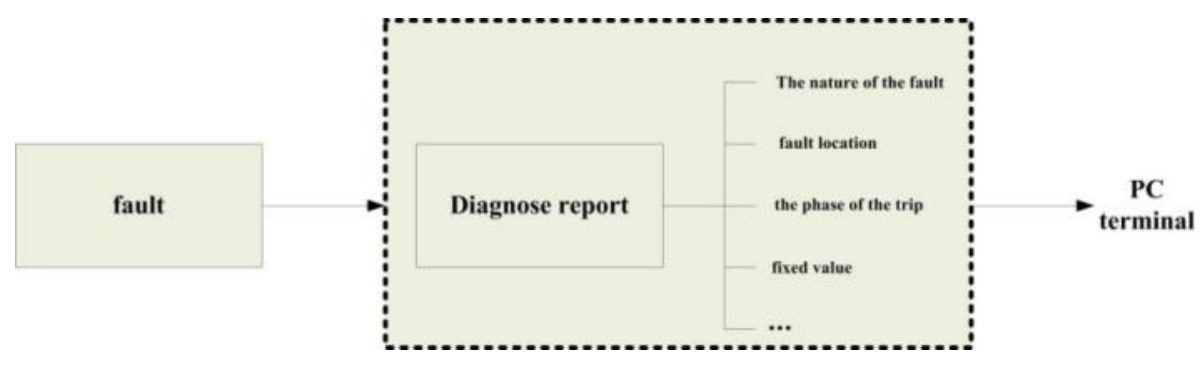

Fig.2 Schematic diagram of intelligent fault diagnosis

\subsection{Fault file management}

Archive and manage the fault diagnosis report generated by the power grid fault diagnosis report module to form a power grid fault history database, provide intelligent recommendation modules to realize automatic push of similar faults; have the power grid fault diagnosis report editing function, realize the addition of protection action information, waveform lists, Delete, modify and other functions; can query the power grid fault diagnosis report according to the operation and maintenance unit, plant name, voltage level, primary equipment type, primary equipment name, fault type, intelligent matching, etc. In addition, the problems found in the failure analysis can create protection equipment defects, countermeasures, and family defects.

\subsection{Online configuration files management}

For smart substations protected by the "Nine Unifications", the virtual loop CRC check code of the device is regularly checked whether it is consistent with the latest version of the SCD file. When the device's operating configuration is found to be inconsistent with the SCD, an alarm is issued to remind relevant personnel to submit the latest version of the SCD file. The flow chart is shown in Fig.3.

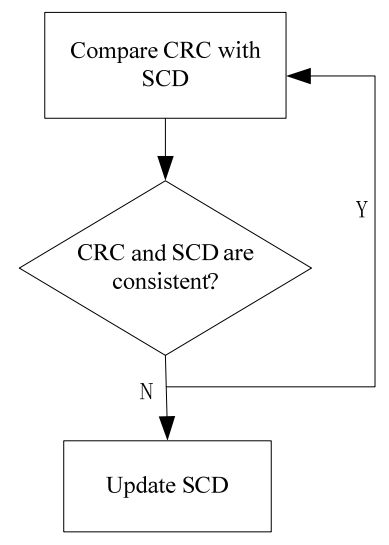

Fig.3 Flow chart of online management of configuration files

\subsection{Run fixed value online check}

Periodically check the difference between the published fixed value and the device operating fixed value, and if the difference is found, it will be sent to the relevant personnel to send an alert, and it will be displayed on the control cloud through the corresponding interface.

\subsection{Online check of pressure plate status}

For smart substations, the secondary equipment is used to monitor and analyze the pressure plate information sent by the sub-stations, perform automatic inspection of the pressure plate status, and find the pressure plate that is inconsistent with the default state and give an alarm.

\subsection{Equipment status evaluation}

Evaluate the health status and current operating status of the secondary equipment in operation, generate comprehensive evaluation results, fully grasp the health status of the equipment, predict the risk operation level of the secondary equipment and power system, and the reliability of the equipment, and provide a basis for accurate state maintenance.

\section{7 equipment risk warning}

Use equipment health status evaluation and online status evaluation result data, equipment defect statistical analysis result information, equipment history and real-time alarm information, equipment history and real-time online monitoring information, status displacement information, substation protection configuration information, etc., to analyze and obtain comprehensive equipment risks, Realize early warning of equipment evaluation, state early warning and group trend early warning. The schematic diagram is shown in Fig.4. 


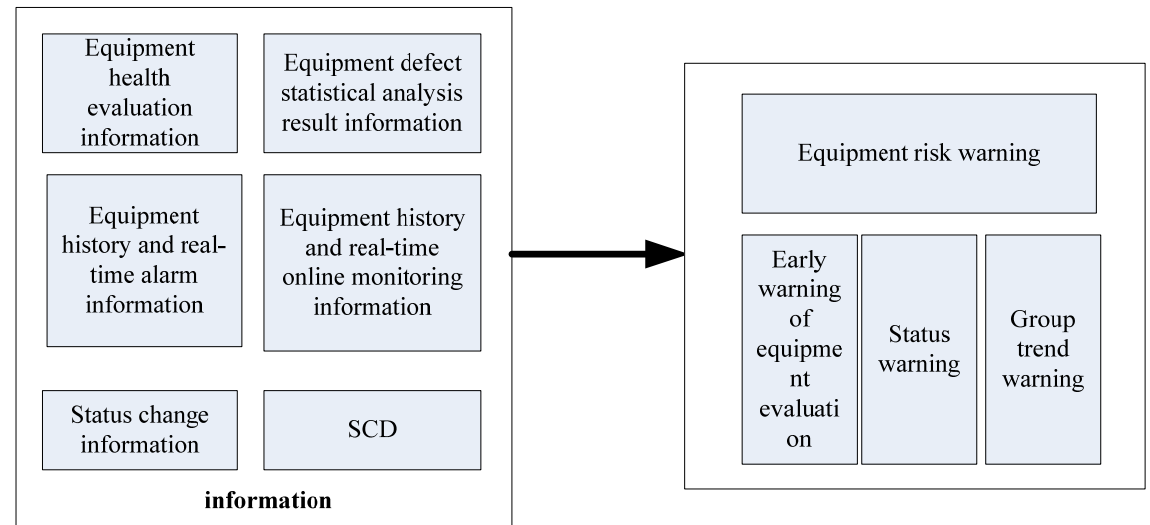

Fig.4 Schematic diagram of equipment risk warning

\section{Conclusion}

This paper proposes the on-line monitoring system architecture of secondary equipment in smart substations, and analyzes the specific application in detail, advances the level of online monitoring and analysis of secondary equipment, improves the technical support ability of regulation and control operation, and improves the level of secondary equipment operation management.

\section{Acknowledgments}

This work was supported by Research on Design Technology of Secondary System of Smart Substation Based on Physical Information Fusion from Science and Technology Project of State Grid Corporation (5200-202056139A-0-0-00).

\section{References}

1. ZHANG Yanxu, CAI Zexiang, LI Xiaohua, et al. Analytical modeling of traffic flow in the substation communication network[J]. IEEE Transactions on power delivery, 2015,30(5):2119-2127.

2. CHEN Anwei, YUE Quanming, ZHANG Zongyi, et al. Engineering application of primary equipments on-line monitoring system in smart substation[J]. Automation of Electric Power System, 2017, 36(13): 110-115.

3. Yang Liang. Discussion online monitoring and condition based maintenance technology for power primary equipment[J]. Telecom power technology, 2018, 35(9):62-64.

4. SHI Xiuping, BAI Zheng, ZHANG Daonong, et al.Research and development of online monitoring and evaluating system for the dynamic performance of generators-power grid based on PMU data[J].Proceedings of the CSU-EPSA, 2016, 28(12):42-45.

5. LU Jinhai, Dai Zemei, ZHANG Li, et al. On-line power system disturbance monitoring and evaluation method based on WAMS[J]. Automation of electric power system, 2012,36(8):82-86.
6. Ren Shuangzan, Wuhao, LIU Xiaoli, et al. Research status of on-line monitoring technology for dissolved gas in transformer oil[J]. Electric Engineering,2020, (19):86-90.

7. LIU Xiaowei. Research on lightning arrester online monitoring and fault diagnosis system[D]. XIAN polytechnic university,2019.

8. LIU Ting, LIU Bo, SHI Xugang, et al.Equipment maintenance based on online monitoring[J]. Applications, 2020,37(08):36-37.

9. DU Jun, YE Xiang, GE Liqing, et al. Key technologies of online maintenance system for relay protections in smart substation and its implementation $[\mathrm{J}]$. Electric Power automation equipment, 2016,36(7):163-169.

10. LIU Kun, HUANG Minghui, LI Yiquan, et al. Research on online operation method for protective relay of smart substation[J]. Power System protection and control, 2020,48(7):58-65.

11. HUA Lei, HUANG Chenkai. Aging prevention and online monitoring of secondary equipment DC Power Plug[J]. Power \& energy, 2020, 41(1):145-148.

12. XU Changbao, ZHUANG Chen, JIANG Hongtu. Technical research of secondary equipments' state monitoring in smart substation[J]. Power system protection and control, 2015,43(7):127-131. 